\title{
A percepção da criança típica sobre a criança com deficiência em uma escola do ensino regular da rede pública da cidade de Pelotas
}

\author{
Cassiane lacana da Costa \\ Nicole Ruas Guarany²
}

\section{RESUMO}

O presente estudo tem como objetivo identificar a percepção da criança típica em relação à convivência com a criança com deficiência dentro do ambiente escolar, observando suas interações e seu conhecimento referente à deficiência, além de verificar a importância da colaboração de um profissional da terapia ocupacional dentro desse espaço. É um estudo de caráter qualitativo, sendo utilizado como material de avaliação um questionário aberto sobre a percepção da criança típica em relação ao colega com deficiência, um questionário para coleta de dados demográficos e um questionário a ser respondido em forma de desenho pelas crianças. A análise de dados qualitativos de Bardin (1977) foi empregada para interpretar os resultados das entrevistas. Participaram do estudo oito crianças entre 5 e 8 anos de idade. Os resultados demonstraram que as crianças típicas não compreendem o termo deficiência como algo que exclui a participação do colega com deficiência das atividades escolares, entretanto sabem observar as limitações apresentadas. Neste estudo, as crianças típicas não demonstraram preconceito em relação às diferenças, mas reproduziram percepções construídas socialmente, retratando os pensamentos de pessoas de sua convivência sobre a criança com deficiência. Acredita-se que a convivência entre as crianças produz uma sociedade mais diversa e aberta a conviver com as diferenças.

Palavras-chave: Deficiência. Inclusão Escolar. Terapia Ocupacional.

1 Terapeuta Ocupacional, pela Universidade Federal de Pelotas. E-mail : kassianedacosta@ gmail.com

2 Doutora em Ciências Médicas pela Universidade Federal do Rio Grande do Sul. Docente do Curso de Terapia Ocupacional Faculdade de Medicina Universidade Federal de Pelotas. E-mail: nicolegr.ufpel@gmail.com 
The perception of the typical child about the disabled child in a school of regular education of the public network of the city of Pelotas

\section{ABSTRACT}

The objective of this study is to identify the typical child's perception regarding the coexistence with the child with disabilities within the school environment, observing their interactions and their knowledge regarding the disability, as well as to verify the importance of the collaboration of an occupational therapy professional within space. It is a qualitative study, being used as an evaluation material an open questionnaire about the typical child's perception in relation to the colleague with a disability, a questionnaire for the collection of demographic data and a questionnaire to be answered in the form of a drawing by the children. Bardin's (1977) qualitative data analysis was used to interpret the interview results. Eight children between 5 and 8 years of age participated in the study. The results showed that typical children do not understand the term disability as something that excludes the participation of the disabled classmate of the school activities, however they know to observe the presented limitations. In this study, typical children did not show prejudice in relation to differences, but reproduced socially constructed perceptions, portraying the thoughts of people living with them about the disabled child. It is believed that the coexistence between children produces a society more diverse and open to live with the differences.

Keywords: Disability. School Inclusion. Occupational Therapy.

\section{La Percepción del niño típico sobre el niño con discapacidad en una escuela de enseñanza regular de la red pública de la ciudad de Pelotas}

\section{RESUMEN}

El presente estudio tiene como objetivo identificar la percepción del niño típico con relación a la convivencia con el niño con discapacidad dentro del ambiente escolar, observando sus interacciones y su 
conocimiento referente a la discapacidad, además de verificar la importancia de la colaboración de un profesional de la terapia ocupacional dentro de ese espacio. Es un estudio de carácter cualitativo, siendo utilizado como material de evaluación un cuestionario abierto sobre la percepción del niño típico con relación al compañero con discapacidad, un cuestionario para la recogida de datos demográficos y un cuestionario a ser respondido en forma de dibujo por los niños. El análisis de datos cualitativos de Bardin (1977) fue empleado para interpretar los resultados de las entrevistas. En el estudio participaron ocho niños entre 5 y 8 años de edad. Los resultados demostraron que los niños típicos no entienden el término deficiencia como algo que excluye la participación del compañero con discapacidad de las actividades escolares, sin embargo saben observar las limitaciones presentadas. En este estudio, los niños típicos no mostraron prejuicio con relación a las diferencias, pero reprodujeron percepciones construidas socialmente, retratando los pensamientos de personas de su convivencia sobre el niño con discapacidad. Se cree que la convivencia entre los niños produce una sociedad más diversa y abierta a convivir con las diferencias.

Palabras clave: Discapacidad. Inclusión Escolar. Terapia Ocupacional.

\section{Introdução}

Segundo Oliveira (2002), a consciência reflexiva e o controle deliberado, as principais funções psicológicas superiores, são questões muito importantes no aprendizado escolar da criança, pois fatores que antes eram involuntários e espontâneos, como a memória e a atenção, precisam se transformar em sistemas voluntários e orientados, por isso estimular a criança nesses níveis de consciência e controle auxilia no desenvolvimento intelectual da mesma.

Para que a aprendizagem da criança aconteça de forma efetiva, a mesma precisa estar engajada positivamente dentro do ambiente escolar. Esse processo envolve o bom relacionamento com os outros colegas, além da socialização nas atividades que envolvem a participação em grupo tanto dentro como fora da escola. A inclusão de crianças com deficiência não está mais apenas no papel. Hoje ela aparece em grande parte das escolas regulares brasileiras, sejam públicas ou privadas. E o 
convívio entre as crianças consideradas típicas e aquelas com deficiência se apresenta potencializador de experiências ricas de aprendizagens, para além do ensino, para todos que se inserem no ambiente escolar: professores, crianças, funcionários e familiares.

Dentro desse aspecto, de que a escola é um ambiente importante na formação social e tanto quanto intelectual da criança, é que muitos conceitos se estabelecem dentro desse ambiente. Torna-se então pertinente destacar o que Oliveira $(2002$, p. 43, 44) diz:

\begin{abstract}
A escola é um espaço social relevante na vida das pessoas, onde as relações se estabelecem de forma dinâmica e no cotidiano. Nesse sentido, é um espaço no qual podemos vislumbrar preciosas transformações nas representações sociais, através da discussão de conceitos, teorias, postulados e do debate de ideias para que possamos construir concepções diferenciadas sobre o próprio papel da educação, dos professores e dos próprios alunos.
\end{abstract}

De acordo com Maciel (2000), o processo de exclusão social das pessoas com deficiência é muito antigo e ocorre em diversos âmbitos: social, escolar ou profissional. Contudo, é através da inclusão escolar, bem como das mudanças sociais, do cumprimento de leis, do uso de novas tecnologias e verbas destinadas para programas sociais que essa situação pode ser mudada. Segundo o Ministério da Educação (2014), a educação inclusiva é um movimento mundial e uma ação política, cultural, social e pedagógica, que traz a todos os estudantes o direito de estarem juntos, sem que haja descriminação.

Conforme Alcântara et. al. (2016), é relevante destacar que a Política Nacional de Educação Especial de 2008 indica que em uma perspectiva inclusiva, espaços como o Atendimento Educacional Especializado (AEE) auxiliam na promoção do processo de participação da criança com deficiência. Entretanto, questiona-se se todas as diferenças serão trabaIhadas dentro dessas salas especializadas ou se não será preciso criar novas formas de se pensar outras fontes de apoio com relação à escolarização dessas crianças que não as exclua do ambiente em que convivem com as crianças típicas.

Dentro da escola é fundamental que se realizem ações que visem à inclusão através da desconstrução de preconceitos constituídos socialmente, muitas vezes, pela falta de informação. Todas as atividades 
precisam ser desenvolvidas com os profissionais, alunos e a comunidade, pois é através delas que o processo de mudança da percepção de deficiência e da relevância da presença da criança com deficiência nesse ambiente irá acontecer (BRIANT et. al. 2012).

As diferenças podem ser enxergadas de diversas formas pelas crianças, sendo essas positivas ou negativas. Uma interpretação errada na forma em que um adulto fala com uma criança pode gerar diversos problemas, principalmente dentro do ambiente escolar, considerando que muitas vezes as crianças reproduzem conceitos criados socialmente, e transmitem isso dentro da sala de aula. Os conflitos escolares entre alunos podem começar através dessas reproduções, gerando assim uma série de aspectos negativos na vida da criança que está sendo vítima (GUEDES, SILVA, 2012).

O bullying, caracterizado por agressões física, verbal ou psicológica, está presente no ambiente escolar desde sempre, mas passou a ser estudado apenas nas ultimas décadas. Os profissionais preocuparam-se em identificar agressões capazes de formar traumas, muitas vezes, irreversíveis. É importante que todos os profissionais possam discutir esse assunto na comunidade escolar (LEMOS 2007). Acredita-se que através de campanhas e da presença dessas pessoas na sociedade, o preconceito e a discriminação deem lugar ao convívio saudável entre aqueles que possuem deficiência e os que não possuem, mudando seu cotidiano e induzindo-as a novas descobertas (ANTUNES, 2016).

Muitas vezes as crianças com deficiência são excluídas de atividades escolares por serem vistas como diferentes e incapazes de realizar determinadas tarefas. Isso acaba prejudicando seu desenvolvimento escolar, e é neste momento que a participação de um profissional como o terapeuta ocupacional, por exemplo, pode auxiliar, mediando essa situação (SANCHES, TEODORO, 2006). Quando a criança apresenta transtornos no desempenho ocupacional, não consegue se engajar ou desempenhar ocupações bem como efetivar atividades dentro de um ambiente e/ou contexto, na concepção da terapia ocupacional, essa criança se enquadrará dentro do atraso ou desvio de desenvolvimento (CAVALCANTI, GALVÃO, 2014).

O Terapeuta Ocupacional dentro do ambiente escolar não está atrelado a apenas à adaptação de ambientes e materiais que visam à melhora em diversos aspectos da criança com deficiência. Esse profissional tem um papel fundamental na inclusão eficiente dessa criança, 
pois contribui com diversos assuntos e métodos que envolvem desde a percepção da criança típica sobre deficiência até como essas crianças enxergam essa deficiência, além de trabalhar o engajamento e o convívio social dessas crianças, o trabalho em grupo, a orientação dos profissionais, a colaboração em ações que envolvam a comunidade e que estão relacionadas tanto às crianças com deficiência às crianças sem deficiência (BRIANT et. al. 2012).

Observando o quanto a temática em questão ainda é pouco estudada, este estudo teve como objetivo identificar a percepção da criança típica em relação à criança com deficiência dentro do ambiente escolar, observando suas interações e seu conhecimento referente à deficiência, além de verificar a importância da colaboração de um profissional da terapia ocupacional dentro desse espaço.

\section{Metodologia}

Trata-se de um estudo de caráter qualitativo e exploratório. O estudo foi realizado no ano de 2018 em uma escola municipal de um bairro socialmente vulnerável da cidade de Pelotas, Rio Grande do Sul. Participaram crianças típicas, com idade entre 5 e 8 anos, que eram colegas de sala de aula de crianças com deficiência. Os critérios de inclusão foram crianças típicas entre 5 e 12 anos de idade, que fossem colegas de sala de aula de crianças com deficiência e que fossem autorizadas pelos pais, através da assinatura do Termo de Consentimento Livre e Esclarecido (TCLE), a participar da pesquisa.

Foram utilizados três questionários para observação das variáveis: um questionário para coletar informações sociodemográficas das crianças, como idade, sexo e série escolar, além de conter informações sobre a escola relacionadas à acessibilidade e inclusão (se possui sala de AEE, rampas ou elevadores, banheiros adaptados ou outros dispositivos de acessibilidade); um questionário contendo 5 perguntas abertas a serem respondidas de forma livre pelas crianças sobre a convivência com crianças com deficiência e sua percepção sobre as mesmas; e um último questionário, que deveria ser respondido pelas crianças em forma de desenho para os quais foram distribuidos folha de papel A4 e lápis de cor. O questionário de perguntas abertas foi realizado em formato de roda de conversa e as atividades foram gravadas em forma de áudio. Os instrumentos foram aplicados em um único momento aos participantes. 
Antes da aplicação dos questionários para as crianças, um vídeo amplamente divulgado em redes sociais em que crianças e adultos imitam expressões faciais de outras crianças, sendo uma delas com Paralisia Cerebral, foi apresentado para introduzir a discussão sobre o tema.

Para análise dos resultados foi aplicada a Análise de Conteúdo, segundo Bardin (1977), que é composta por diversas técnicas para analisar o conteúdo das mensagens expressas pelo indivíduo. Dentre essas técnicas a mais utilizada e indicada por sua eficácia na aplicação em discursos diretos é a técnica de análise temática ou categorial (BARDIN, 1977).

A pactuação com a instituição foi realizada, primeiramente, por meio da apresentação do estudo e de seus objetivos aos responsáveis da escola e, após, foi realizado contato com a Secretaria Municipal de Educação da cidade de Pelotas para confirmar a autorização para a realização do estudo. Esta pesquisa foi submetida à Plataforma Brasil e autorizada pelo Comitê de Ética e Pesquisa da Universidade Federal de Pelotas, por meio do CAAE: 81775317.7.0000.5317

\section{Resultados e discussão}

A escola municipal participante deste estudo localiza-se em um bairro carente da cidade de Pelotas, possui em suas dependências uma sala de AEE (Atendimento Educacional Especializado), além de um banheiro adaptado para deficientes físicos. Sobre os recursos de acessibilidade, a escola possui rampa móvel para as salas de aula e por ser térrea, não possui elevadores. Não foram informados recursos para pessoas que possuam alterações visuais ou auditivas.

Participaram do estudo 8 crianças, cinco do sexo feminino e três do sexo masculino. A idade das crianças variou entre 5 e 8 anos de idade, sendo uma criança com 5 anos, cinco crianças com 7 anos e duas crianças com 8 anos.

A dinâmica de entrevistas se deu da seguinte forma: a coordenadora da escola conduziu as crianças até uma sala fornecida para a realização do estudo, onde foram passadas explicações sobre as atividades e o vídeo com temática de deficiência. Após esse momento, as crianças fizeram um desenho em uma folha A4 em relação ao seu entendimento sobre o assunto abordado.

As perguntas realizadas no grupo de discussão foram respondidas pelas crianças livremente e cada criança teve oportunidade de 
responder as questões à medida que se sentiam à vontade. As entrevistas foram gravadas em áudio e transcritas para se realizar Análise de Conteúdo das mesmas. Da leitura flutuante realizada do conteúdo das mensagens, foram retiradas declarações que evidenciassem as categorias que surgiram das respostas das crianças.

As categorias temáticas constituídas foram: Percepção sobre a temática do vídeo; Conceito de deficiência; O que é deficiência; Colega diferente; Igual ou Diferente; Interação social; Ambiente escolar. Discutiu-se cada uma das categorias, analisando-se o conteúdo trazido pelas crianças, entretanto, destaca-se que os autores decidiram por não alterar a fala das crianças apresentando-as em sua forma literal e linguagem coloquial.

A categoria Percepção sobre a temática do vídeo indicou que a maioria das crianças disse que o filme era sobre imitar o que os outros faziam ( $n=4)$, uma criança relatou que o filme quis mostrar que se deve respeitar as pessoas $(n=1)$ e outra criança disse que não se pode fazer bullying com as pessoas $(n=1)$. Duas crianças não quiseram responder.

As crianças desse estudo indicaram possuir conhecimento sobre o que é bullying e como essa atitude pode prejudicar sua vítima. Malta et. al. (2010) diz que o bullying é um tema extremamente relevante dentro do contexto escolar e que os profissionais devem compreender a importância de medidas que visam à sua prevenção ou redução. Entender e estar engajado no processo de construção das identidades, bem como perceber como as diferenças e os preconceitos estão presentes no ambiente escolar é uma forma de colaborar para que esse ambiente se torne mais inclusivo e democrático, além de contribuir para o entendimento sobre casos de violência entre os alunos. (SALLES et al, 2008).

Omete (2006) relata que no processo de construção da educação inclusiva os educadores brasileiros tratam as questões das diferenças e das diversidades entre os alunos de forma ainda muito simples e que essas questões necessitam ser discutidas amplamente dentro dos espaços educacionais.

Na categoria Conceito de deficiência foi questionado às crianças se elas conheciam o termo deficiência. A maioria relatou não conhecer essa palavra $(n=5)$, outras afirmaram conhecer $(n=2)$ e uma criança disse que achava conhecer o termo. Essa diferença pode ser observada nos relatos a seguir: 
"Ninguém fala" (referente à palavra deficiência) (Criança 5).

"Eu acho que eu já ouvi minha mãe falando" (Criança 7).

Silva (2018) destaca que o adulto tem um papel importante nos processos de aprendizagem da criança. O professor é parte fudamental na interação entre a criança típica e a criança com deficiência, e é por meio dele, dentro do ambiente escolar, que a criança terá aprendizados e experiências que o tornarão um adulto com percepção em relação ao outro.

A exploração desse tema dentro do ambiente escolar, com a participação direta do aluno com e sem deficiência é extremamente relevante, pois segudo Batista e Enumo (2004) a interação social e a aceitação por parte dos alunos típicos sobre o colega com deficiência não é fundamental apenas para avaliar as consequências da não aceitação e interação entre os pares, mas também para ajudar no processo de criação de práticas educacionais inclusivas, que tenham como objetivo trabalhar as questões de aceitação e interação social dessas crianças.

Ainda assim é relevante destacar o quanto é importante que assuntos que estejam relacionados à deficiência sejam abordados tanto no ambiente escolar, como no cotidiano dessa criança fora desse ambiente. Nesse sentido, a participação dos pais ou responsáveis se torna primordial para o entendimento dessa criança, visto que normalmente as crianças cometem erros de interpretação em relação à deficiência, pois elas têm mais dificuldade em entender uma deficiência do que uma doença, uma vez que elas não podem viver de forma mais concreta a experiência da deficiência e acabam associando à doença (FERLAND, 2009).

Na categoria $O$ que é Deficiência, as crianças foram questionadas sobre o que achavam que era deficiência. A metade das crianças manteve-se em silêncio durante a pergunta ou não soube responder $(n=4)$, outros relacionaram a alguma doença ou condição de saúde alterada $(n=2)$, e também relacionaram com alguém que faz uso de algum equipamento de tecnologia assistiva $(n=2)$, como pode ser observado nos trechos a seguir:

"Sabe que meus colegas têm piolho" (quando questionada se achava ter algum colega diferente na sala de aula) (Criança 1)

"É alguém que tem que ficar na cadeira de rodas porque tem problema." (Criança 2) 
"É uma pessoa que tem problema no ouvido e que fala muito." (Criança 3)

"É uma doença [...] Eu acho que é a uma... eu acho que é AIDS, essas coisas [...]." (Criança 8)

Um estudo realizado por Ferland (2009) identificou que a noção de deficiência não é compreendida com facilidade pelas crianças. Elas têm dificuldade em estabelecer a distinção entre uma deficiência e uma doença passageira, contudo, indica que é sustentando-se em suas próprias experiências, isto é, na sua relação social e afetiva com crianças que apresentam suas capacidades e habilidades limitadas, que elas conseguem perceber melhor o que é a deficiência.

Antunes (2016) explica que nossa sociedade, muitas vezes, resume a criança que possui uma deficiência apenas a um deficiente e que o preconceito e as comparações com as crianças típicas acabam por prejudicar a participação social dessas crianças que possuem uma riqueza emocional e afetiva única.

Em relação à categoria Colega diferente foi questionado às crianças se elas identificavam algum colega que apresentasse algo diferente delas, metade das crianças relataram ter colegas com alguma diferença $(n=4)$, outros responderam que não possuem colega diferente ou com deficiência na sala de aula $(n=2)$ e o restante relatou que a professora disse que eles possuem um colega diferente na sala de aula, mas que não reconhecem a diferença do colega $(n=2)$. Como pode ser descrito no trecho a seguir:

"[...] a professora diz que a gente tem um colega que tem problemas." (Criança 2)

A temática dessa categoria apresenta uma informação muito importante para pensar sobre a inclusão: a forma como a deficiência das crianças é apresentada e trabalhada no ambiente escolar. A escola e a família são dois grupos fundamentais no sucesso ou no fracasso da aprendizagem das crianças, por isso os educadores, por meio de suas condutas, além da postura e da maneira de lidar com relação a essas crianças, precisam estimulá-las adesenvolver não só o saber e a aprendizagem, mas a lidar com a diferença e a diversidade social e cultural (LEMOS, 2007).

A escola, certas vezes, acha que está protegendo a criança com deficiência caracterizando-a como deficiente ou incapaz criando alternativas e recursos únicos e exclusivos para ela acreditando estar contri- 
buindo para sua inclusão, mas ao invés disso está criando uma imagem estereotipada da criança, que a exclui e a expõe a preconceitos, fazendo com que essa criança desenvolva essa imagem de si mesmo (JURDI, AMIRALIAN, 2006).

E como Antunes (2016) diz:

“No meio da diferença, existe uma beleza muitas vezes invisível aos olhos, mas sensível ao coração quando este se permite a sentir. Uma criança nasce, primeiro ela é criança, depois uma criança portadora de deficiência."

Na categoria Igual ou Diferente, que perguntava às crianças se elas achavam que uma pessoa que não enxerga, não ouve e não possui uma perna são iguais ou diferentes de outras pessoas, a maioria das crianças classificou como diferente uma pessoa que não enxerga $(n=7)$, uma pessoa que não ouve $(n=7)$ e uma pessoa que não possui uma perna ou utiliza cadeira de rodas $(n=6)$. Entretanto estas mesmas características não foram associadas como diferenças entre as pessoas por duas crianças. $\mathrm{O}$ trecho a seguir representa essa categoria:

“Eu acho que ela não é diferente porque mesmo não conseguindo ver, ela consegue sentir as coisas, ela consegue tocar nas coisas.. no lápis, na borracha [...]" (Criança 8)

Em relação à categoria Interação social, as crianças que participaram do estudo relataram ser amigo do colega com deficiência ou convidar o mesmo para brincar $(n=3)$, o restante $(n=5)$ relatou não ser amigo do colega ou não convidar o mesmo para brincar

\author{
“[...] ele fica gritando [...]" (Criança 6) \\ “[...] não brinco com ele nunca, ele fica estudando... eu \\ fico estudando[...." (Criança 6) \\ “[...] mas às vezes não dá porque ele fica mais nervoso \\ ainda.[...]".(Criança 6)
}

Observa-se que as crianças deste estudo sentem-se ainda inseguras quanto ao processo de inclusão, principalmente no que diz respeito à socialização. Nao sabem como devem interagir, quais as brincadeiras podem ser realizadas e como devem se relacionar com a criança deficiente. Um estudo realizado por Mandich, Polatajko e Rodger (2003), citado por 
Takatori (2012), diz que crianças com problemas motores encontram na infância dificuldades em participar de atividades típicas de suas idades, o que pode fazer com que isso cause atraso na sua aprendizagem e no seu desenvolvimento psicossocial. As restrições nas atividades cotidianas acabam por aumentar os problemas dessas crianças, que muitas vezes se tornam mais complicados do que as incapacidades da deficiência.

Jurdi e Amiralian (2006) dizem que uma das propostas para a inclusão das crianças com deficiência no ambiente escolar deve se iniciar com a construção de um ambiente lúdico, que proporcione às crianças relações mais coletivas e menos individualizadas, onde uma cultura contribua para a construção de outra cultura de uma forma autônoma e solidária.

Batista e Enumo (2004) acreditam que a inclusão escolar de crianças com necessidades especiais é uma forma de criar oportunidades de interação social com outras crianças, além de diminuir o preconceito e evitar o isolamento. Após as crianças entenderem o significado de grupo é fundamental que a presença de crianças com deficiência dentro da escola seja estudada, na intenção de perceber seu papel na interação junto ao outro diante da sociedade.

Em relação à interação social e ao brincar Braccialli (2004) nos diz que:

\begin{abstract}
"Ao brincar e jogar, diversos aspectos são estimulados, desenvolvidos ou aperfeiçoados: a criatividade; a memorização; a cooperação e solidariedade; a concentração; a linguagem; a motivação; a aquisição de conceitos; a motricidade; a capacidade de discriminar, julgar, analisar, tomar decisões e aceitar críticas; a competitividade; a socialização; a confiança em si e em suas possibilidades, o respeito às regras e o controle emocional."
\end{abstract}

Souza e Batista (2008) destacam que da mesma forma que as criança típicas estabelecem e sustentam interações uns com os outros, as crianças com deficiência através de situações de brincadeira livre e em grupo são capazes de criar um ambiente propício para a criação dessas interações.

O convívio no ambiente escolar de crianças típicas e de crianças com deficiência tem um papel muito importante, pois é por meio dessa interação na educação inclusiva que as crianças típicas terão compreensão das diferenças e diversidades, se tornando seres mais abertos, com menos preconceitos e que respeitam as diferenças (SILVA, 2018). 
Na categoria Ambiente Escolar, as crianças foram questionadas sobre a escola ser ou não um ambiente inclusivo para o colega que tem deficiência. Metade das crianças respondeu que acham a escola um ambiente bom para o colega $(n=4)$.

Segundo Antunes (2016), ao incluir pessoas com deficiência, a escola se transformou em um ambiente propício à aprendizagem, mas para que isso aconteça é preciso que a escola possua profissionais qualificados, além de recursos e de um ambiente que forneça o que essa criança necessita, respeitando o ritmo individual de aprendizagem e as limitações da mesma. Intervir apenas junto à criança com deficiência não é o suficiente. É preciso que a escola trabalhe com os outros colegas que convivem com ela para promover práticas educativas que contribuam para aceitação e a interação social nesse ambiente (BATISTA; ENUMO 2004).

É relevante que dentro dos ambientes escolares existam recursos para atender as necessidades desses alunos, além de espaços adaptados e livres de obstáculos, e que todos os profissionais trabalhem para o pleno desenvolvimentos da criança com deficiência, contribuindo para a educação de forma integral e auxiliando na descoberta de novas formas de interação (LOPES, 2012).

Ao final das entrevistas foi solicitado às crianças que realizassem um desenho sobre o que havia sido discutido e o que tinham entendido. Além disso, as crianças foram incentivadas a descrever o que haviam desenhado. A maioria indicou que havia desenhado o colega de sala de aula que consideravam como diferente $(n=5)$ (Figura I).

A criança 1 descreveu a diferença entre as pessoas a partir da cor da pele diversa (Figura II), e o restante fez o desenho com relação direta a alguma deficiência ( $n=2)$ (Figuras III e IV).

\footnotetext{
"Aqui é uma pessoa que não tem uma perna brincando com outra que tem uma perna e ela tá ajudando... é uma pessoa que tem deficiência, mas não importa se tem uma doença ou não... E mesmo se a pessoa precisa de ajuda ela ajuda, porque ela é uma amiga de bom coração[...]" (Criança 8)

"É uma pessoa na cadeira de rodas" (referindo-se ao desenho que fez) (criança 7)

“Eu fiz o A. e a mãe dele" (desenhou o colega diferente) (Criança 5)
} 
Figura 1 - Desenho das Crianças

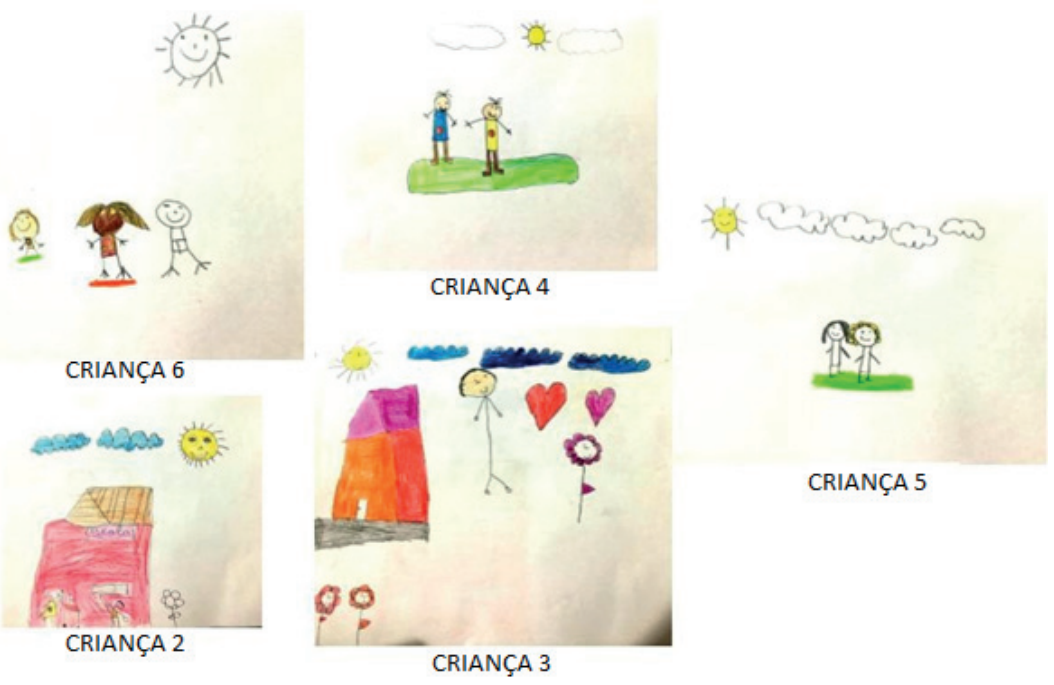

Fonte: próprio autor.

Figura 2, 3 e 4 - Desenho das Crianças.

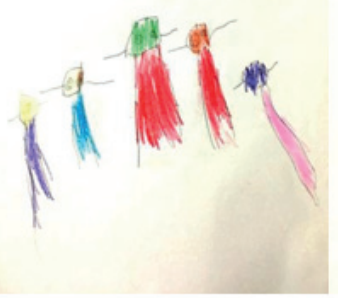

CRIANÇA 1
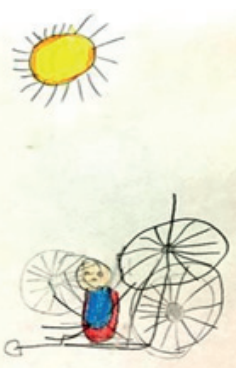

CRIANÇA 7
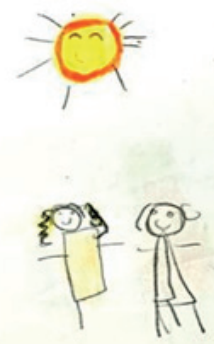

CRIANÇA 8

Fonte: próprio autor.

Muito antes de inserir-se no ambiente escolar, o desenho já aparece no cotidiano da criança. $O$ que muda é a forma de grafismo, desde a sua entrada neste universo (SILVA, 1998).

Em relação a isso Silva (1998) diz que:

Assim como uma pessoa só aprende a expressar-se oralmente se conviver com falantes, a criança desenha porque vive em uma cultura que tem na ativida- 
de gráfica uma de suas formas de expressão. O desenvolvimento do grafismo é marcado pelas interações sociais, o que equivale a afirmar a sua constituição social.

A partir dos resultados deste estudo, pode-se pensar na possibilidade de atuação do terapeuta ocupacional no ambiente escolar. Segundo Ide et. al. (2011) o objetivo da Terapia Ocupacional dentro do ambiente escolar é incluir a criança com deficiência, além de proporcionar a essa criança a experimentação de atividades que tenham como objetivo promover o seu desenvolvimento global, e também de superar dificuldades e aprimorar capacidades e habilidades. Trabalhar junto à criança sem deficiência, mostrando-Ihe que dentro da sociedade existem pessoas singulares, com diversas características que precisam e devem ser respeitadas.

Por isso, dentro do ambiente escolar o terapeuta ocupacional pode estimular o aperfeiçoamento do pensar e do agir das pessoas envolvidas nesse ambiente, sejam elas, crianças, profissionais ou a comunidade num geral, além de promover a construção de grupos e solucionar problemas dos mesmos, contribuindo no ambiente de uma forma geral (ROCHA 2007).

\section{Considerações finais}

Com os resultados deste estudo, foi possível observar que o conceito de deficiência é conhecido pelas crianças de forma pouco aprofundada e que estes parecem reproduzir percepções de pessoas de seu convívio quanto à compreensão de determinados assuntos. Acredita-se que abordar questões que tratem de deficiência, diferença e diversidade em geral produzirá um ambiente mais inclusivo, aberto às discussões necessárias para ampliar as experiências das crianças.

Identificou-se que as crianças típicas interagem, mesmo que brevemente, com o colega de sala de aula que possui uma deficiência, mas que isto não parece ser algo estimulado pela escola ou pelos professores. Saber lidar com as diferenças vai além de produzir um ambiente fisicamente inclusivo (recursos adaptados para aprendizagem ou para circulação, por exemplo). É necessário que as crianças sejam apresentadas ao brincar inclusivo com a construção de relações lúdicas e socialmente participativas. Contudo, observou-se que as crianças não parecem demonstrar preconceito, tampouco excluem o colega com deficiência. 
Em relação ao entendimento sobre o processo de inclusão da criança com deficiência no ambiente escolar, pode-se perceber que, embora as crianças não tenham compreensão da palavra deficiência, elas conseguem perceber dentro desse ambiente que possuem algum colega de sala de aula com deficiência/diferença e entendem a relação da escola ser um ambiente importante e estimulante para esse colega se desenvolver.

O estudo tinha por proposta metodológica conduzir as atividades no formato de grupo de discussão dividido pela faixa etária das crianças, contudo um número pequeno de pais aceitou que seus filhos participassem da pesquisa. Neste sentido, sugere-se que novos estudos sejam realizados para aumentar a relevância desse tema e evidenciar que a contribuição do profissional de Terapia Ocupacional dentro desse ambiente é importante para estimular o convívio entre as crianças, o respeito às diferenças e à inclusão de métodos de aprendizagem e participação social que favoreça a todos no ambiente escolar.

\section{Referências}

ALCÂNTARA, J. N. et al. Formação continuada na perspectiva inclusiva: A relação entre professores do AEE e da sala comum. Teoria e Prática da Educação, v. 19, n. 1, p. 7-24, 2016.

ANTUNES, Solange. A percepção da comunidade escolar sobre a realidade das pessoas com deficiência intelectual ou múltipla. Universidade do Sul de Santa Catarina. Tubarão - SC, 2016.

BARDIN, L. Análise de conteúdo. Lisboa: Edições 70, 1977.

BATISTA, M. W; ENUMO, S. R. F; Inclusão escolar e deficiência mental: análise da interação social entre companheiros. Estudos de psicologia, v. 9, n. 1, p. 101-111, 2004.

BRACCIALLI, L. M. P; MANZINI, E. J; REGANHAN, W. G. Contribuição de um programa de jogos e brincadeiras adaptados para a estimulação de habilidades motoras em alunos com deficiência física. Temas sobre Desenvolvimento, São Paulo, v. 13, n. 77, p. 37-46, 2004.

BRIANT, Maria Emília Pires et al. Inclusão de crianças com deficiência na escola regular numa região do município de São Paulo: conhecendo 
estratégias e ações. Revista brasileira de educação especial, v. 18, n. 1, p. 141-154, 2012.

CAVALCANTI, A.; GALVÃO, C. Terapia Ocupacional: fundamentação e prática. Rio de Janeiro: Guanabara Koogan, 2014. 531 p.

FERLAND, F. Além da deficiência física ou intelectual: Um filho a ser descoberto. 1 ed. Londrina: Lazer e Sport, 2009. 1-225 p.

FOLHA, D. R. S. C; MONTEIRO, G. S; Terapia Ocupacional na atenção primária à saúde do escolar visando a inclusão escolar de crianças com dificuldades de aprendizagem. Revista Interinstitucional Brasileira de Terapia Ocupacional- REVISBRATO, v. 1, n. 2, p. 202-220.

GUEDES, G. V. F;SILVA, J. S; O fenômeno bullying e sua interferência na vida escolar do aluno. In. COLOQUIO INTERNACIONAL EDUCAÇÃO E CONTEMPORANEIDADE, 6., São Cristóvão. Anais [...] São Cristovão, 2012.

IDE, M. G; YAMAMOTO, B. T; SILVA, C. C. B; Identificando possibilidades de atuação da Terapia Ocupacional na inclusão escolar/Identifying possible performances of occupational therapy in school inclusion. Cadernos Brasileiros de Terapia Ocupacional, v. 19, n. 3, 2011.

JURDI, A. P. S; AMIRALIAN, M. L. T M; A inclusão escolar de alunos com deficiência mental: uma proposta de intervenção do terapeuta ocupacional no cotidiano escolar. Estudos de psicologia, v. 23, n. 2, p. 191-202, 2006.

LEMOS, A. C. M; Uma visão psicopedagógica do bullying escolar. Revista Psicopedagogia, v. 24, n. 73, p. 68-75, 2007.

MACIEL, Maria Regina Cazzaniga. Portadores de deficiência: a questão da inclusão social. Perspec., São Paulo, v.14, n.2, p.51-56, 2000.

MALTA, D. C. et al. Bullying nas escolas brasileiras: resultados da Pesquisa Nacional de Saúde do Escolar (PeNSE), 2009. Ciência \& Saúde Coletiva, v. 15, n. 2, 2010.

OLIVEIRA, Anna Augusta Sampaio de. Construção de um sistema educacional inclusivo: um desafio político-pedagógico. Ensaio: Avaliação e Políticas Públicas em Educação, p. 511-524, 2002.

OMOTE, S. Inclusão e a questão das diferenças na educação. Perspectiva, v. 24, n. 3, p. $251-272,2006$ 
ROCHA, E. F. A Terapia Ocupacional e as ações na educação: aprofundando interfaces. Revista de Terapia Ocupacional da Universidade de São Paulo, v. 18, n. 3, p. 122-127, 2007.

SALLES, L. M. F. et al. Diferenças, preconceitos e violência no âmbito escolar: algumas reflexões. Cadernos de Educação, n. 30, 2008.

SANCHES, Isabel; TEODORO, António. Da integração à inclusão escolar: cruzando perspectivas e conceitos. Revista Lusófona de educação, $n$. 8, 2006.

SILVA, Marcelo Oliveira. A convivência entre crianças com e sem deficiência e o papel do professor na educação infantil. Revista Educação Especial, v. 31, n. 60, p. 107-118, 2018.

SILVA, S. M. C. Condições sociais da constituição do desenho infantil. Psicologia USP, v. 9, n. 2, p. 205-220, 1998.

SOUZA, C. M. L; BATISTA, C. G; Interação entre crianças com necessidades especiais em contexto lúdico: possibilidades de desenvolvimento. Psicologia: Reflexão e Crítica, v. 21, n. 3, 2008.

TAKATORI, M. $\mathbf{O}$ brincar na Terapia Ocupacional: Um enfoque na criança com lesões neurológicas. São Paulo: Zagodoni Editora; 2012. $176 p$

Recebido: Outubro/2018

Aceito: Abril/2019 